\title{
Unser Lebenswerk
}

Michelangelo wurde einmal gefragt, wie es käme, dass er so wunderbare Werke schaffen könne.

„Es ist ganz einfach“, antwortete er. „Wenn ich einen Marmorblock betrachte, sehe ich die Skulptur darin. Ich muss nur noch das entfernen, was nicht dazugehört.“

Der Meister sagt: „In jedem von uns steckt ein Werk, das darauf wartet, geschaffen zu werden. Es ist der Mittelpunkt unseres Lebens, und wenn wir uns auch noch so sehr betrügen, so wissen wir doch, wie wichtig es für unser Glücklichsein ist.

Meist ist dieses Kunstwerk unter jahrelangen Ängsten, Schuldgefühlen und Unentschlossenheit verschüttet. Doch wenn wir beschließen, alles wegzuräumen, was nicht dazu gehört, wenn wir nicht an unseren Fähigkeiten zweifeln, dann können wir die Aufgabe erfüllen, die uns bestimmt wurde. Dies ist die einzig mögliche Art, ehrenhaft zu leben.“

(Paulo Coelho - Unterwegs) 